\title{
Molecular and Clinical Aspects of Targeting the VEGF Pathway in Tumors
}

\author{
Grzegorz Korpanty, ${ }^{1}$ Laura A. Sullivan, ${ }^{2}$ Elizabeth Smyth, ${ }^{1}$ Desmond N. Carney, ${ }^{1}$ \\ and Rolf A. Brekken ${ }^{2,3}$ \\ ${ }^{1}$ Department of Medical Oncology, Mater Misericordiae University Hospital, Eccles St, Dublin 7, Ireland \\ ${ }^{2}$ Division of Surgical Oncology, Department of Surgery, Hamon Center for Therapeutic Oncology Research, \\ University of Texas Southwestern Medical Center, Dallas, TX 75390, USA \\ ${ }^{3}$ Department of Pharmacology, University of Texas Southwestern Medical Center, Dallas, TX 75390, USA
}

Correspondence should be addressed to Grzegorz Korpanty, greg.korpanty@gmail.com

Received 25 November 2009; Accepted 21 April 2010

Academic Editor: Arkadiusz Dudek

Copyright () 2010 Grzegorz Korpanty et al. This is an open access article distributed under the Creative Commons Attribution License, which permits unrestricted use, distribution, and reproduction in any medium, provided the original work is properly cited.

\begin{abstract}
Tumor angiogenesis is a complex process resulting from many signals from the tumor microenvironment. From preclinical animal models to clinical trials and practice, targeting tumors with antiangiogenic therapy remains an exciting area of study. Although many scientific advances have been achieved, leading to the development and clinical use of antiangiogenic drugs such as bevacizumab, sorafenib, and sunitinib, these therapies fall short of their anticipated benefits and leave many questions unanswered. Continued research into the complex signaling cascades that promote tumor angiogenesis may yield new targets or improve upon current therapies. In addition, the development of reliable tools to track tumor responses to antiangiogenic therapy will enable a better understanding of current therapeutic efficacy and may elucidate mechanisms to predict patient response to therapy.
\end{abstract}

\section{Introduction}

Angiogenesis, the formation of new blood vessels from a preexisting vascular network, is a crucial process during tumor development. New vessels are needed to supply the tumor with nutrients for sustained local growth and to enable distant metastases [1]. The idea of tumors promoting their own angiogenesis through the secretion of then unknown factor(s) was first proposed in the 1930s by Gordon Ide [2]. In 1945, Glenn Algire [3] noticed that tumors grew significantly faster than normal tissues in part because of the ability to stimulate the growth of new vessels to provide oxygen and nutrients. In late 1960s, work by Bruce Warren, Melvin Greenblatt and Philippe Shubik $[4,5]$ supported the crucial role of tumor angiogenesis in malignant tumorigenesis. Their studies confirmed the hypothesis that tumors secrete soluble substances that promote vessel formation. Folkman reported the isolation of such a substance from a Walker 256 carcinoma grown in rats and called it a "tumor angiogenic factor" (TAF). In 1971, Folkman proposed that tumors cannot grow beyond a certain size without inducing angiogenesis and proposed that inhibiting tumor angiogenesis could prevent local tumor growth and formation of distant metastases $[6,7]$. Since then extensive research has focused on the identification of proangiogenic factors produced by tumor cells and strategies to block their action.

In 2004, bevacizumab (Avastin, Genentech, Inc.) became the first antiangiogenic drug approved by the Food and Drug Administration (FDA) for use in patients with metastatic colorectal cancer [8]. Since then bevacizumab has been approved for several other tumor types including breast, renal cell carcinoma, nonsmall cell lung cancer (NSCLC), and glioblastoma. Additionally, other antiangiogenic drugs were developed, such as sunitinib malate (Sutent, Pfizer, Inc.) and sorafenib tosylate (Nexavar, Bayer Pharmaceuticals Corp.), which are FDA approved for renal cell carcinoma and for gastrointestinal stromal tumors and hepatocellular carcinoma, respectively. The results of the antiangiogenic therapy in clinic have been disappointing as compared to the promising data from preclinical animal studies. Therefore, 
there is much to be learned about tumor angiogenesis and how best to utilize antiangiogenic therapy. In this review we will discuss the mechanisms of tumor angiogenesis and clinical application of antiangiogenic therapy.

\section{Molecular Mechanisms of Tumor Angiogenesis}

Growing tumors secrete a number of growth factors that can induce angiogenesis. One predominant factor that stimulates tumor angiogenesis is vascular endothelial growth factor A (VEGF). VEGF was initially identified as Vascular Permeability Factor (VPF) in 1983 by Harold Dvorak and Donald Senger in the conditioned medium of a guinea pig cancer cell line [9]. In 1989, Napoleone Ferrara's group reported the isolation and sequencing of an endothelial cell specific mitogen from pituitary cells and called it VEGF [10]. In the same issue of Science, Daniel T. Connolly reported cloning a gene encoding VPF that turned out to be identical with VEGF [11].

VEGF stimulates proliferation and migration of vascular endothelial cells (ECs). It also promotes survival, inhibits apoptosis, and regulates permeability of ECs. VEGF belongs to a family of growth factors that includes VEGF-B, -C, -D, -E, and placental growth factor (PlGF) [12]. Alternative splicing of the VEGF gene results in formation of four major isoforms of VEGF of varying molecular weights $\left(\mathrm{VEGF}_{121}, \mathrm{VEGF}_{165}, \mathrm{VEGF}_{189}\right.$, and $\left.\mathrm{VEGF}_{206}\right)$. The main difference between these isoforms is bioavailability of VEGF for receptor binding. $\mathrm{VEGF}_{121}$ exists as a highly soluble circulating form while $\mathrm{VEGF}_{206}$ remains bound exclusively to the extracellular matrix (ECM) and is released upon proteolytic cleavage by metalloproteinases (MMPs) or plasmin [13]. VEGF $_{165}$ is the predominantly active isoform that can be found both circulating in plasma and bound to ECM [12].

The biological functions of VEGF are mediated upon binding to receptor tyrosine kinases Vascular Endothelial Growth Factor Receptor-1, -2 (VEGFR1, 2). VEGFR1 binds VEGF, VEGF-B, and PIGF $[14,15]$. VEGFR1 participates in embryonic vessel development, and is proposed to facilitate hematopoiesis and recruitment of endothelial cell progenitors to tumor blood vessels from bone marrow [12]. VEGFR1 binds VEGF with high affinity $\left(K_{D} \sim 10\right.$ $20 \mathrm{pM}$ ), which is significantly stronger than the affinity of VEGF-VEGFR2 interaction. The mechanisms through which VEGFR1 functions have not been elucidated completely. Genetic data suggest that during embryonic development VEGFR1 functions as a negative regulator of VEGF activity. Mice deficient in VEGFR1 (e.g., VEGFR1 $1^{--}$) die in utero from an over abundance of endothelial cells that are disorganized [16]. Furthermore, mice engineered to express VEGFR1 lacking the tyrosine kinase domain ( $\mathrm{flt}-1^{T K-/-}$ ) develop normally with a fully functional vascular network [16]. Additionally, the extent of VEGFR1 involvement in adult angiogenesis is not well-defined [17, 18]. There are numerous reports of selective blockade of VEGFR2 activity in tumors resulting in reduced angiogenesis and tumor growth [19-23] suggesting that VEGFR1 activity is not required for VEGF-induced angiogenesis in pathological conditions. However, the function of VEGFR2 is defined more clearly.

VEGFR2 is the key mediator of VEGF-driven angiogenesis. VEGFR2 is crucial during embryonic vascular development. Heterozygous and homozygous VEGFR-2 knockout mice die in utero due to disrupted vasculogenesis and hematopoiesis [24]. Upon VEGF binding, VEGFR2 undergoes auto-transphosphorylation and downstream effectors including phospholipase $\mathrm{C}$ gamma, protein kinase $\mathrm{C}$, Raf, the MAP kinase signaling cascades, and the PI3K and FAK pathways are activated, leading to endothelial cell proliferation, migration, and survival (Figure 1) $[25,26]$. VEGFR3 binds VEGF-C and -D and is directly involved in formation of the lymphatic vasculature physiologic and tumor development $[27,28]$. There is also experimental evidence that VEGFR3 mediated activation of lymphatic endothelial cells is crucial for metastasis [29]. Neuropilin-1 (Nrp-1) and Neuropilin-2 (Nrp-2) are coreceptors originally identified for their involvement in neuronal guidance, and that bind members of collapsin/semaphorin protein family [30]. The Nrps can also bind to certain heparin binding isofoms of VEGF (e.g., $\mathrm{VEGF}_{165}$ ) to enhance the binding of VEGF to VEGFR1, and VEGFR2 (Figure 1) [31, 32]. Nrps lack tyrosine kinase domains but do contain an intracellular PDZ domain, which has been suggested to facilitate VEGF specific signaling.

VEGF expression within tumors is regulated by oxygen levels, growth factors and cytokines, and oncogene activation/tumor suppressor inactivation [26]. Hypoxia in the tumor microenvironment is one of the most important factors influencing expression of VEGF. Hypoxia inducible factor-1 (HIF-1) is a transcription factor that regulates expression of certain genes in response to intracellular oxygen levels $[33,34]$. It consists of two subunits: alpha $(\alpha)$ and beta $(\beta)$. Normoxic conditions favor ubiquitindependent proteosome-mediated degradation of HIF- $1 \alpha$ subunit, while oxygen deprivation stabilizes and enhances HIF- $1 \alpha /$ HIF- $1 \beta$ dimerization. These dimers interact with a hypoxia response element (HRE) in the promoter region of many genes, including VEGF [35-37]. VEGF expression is also regulated via paracrine or autocrine release of growth factors and cytokines such as platelet-derived growth factor (PDGF), epidermal growth factor (EGF), keratinocyte growth factor, insulin-like growth factor (IGF), transforming growth factors alpha and beta (TGF- $\alpha,-\beta)$, interleukin $1 \alpha$ and 6 (IL- $1 \alpha,-6)$ and prostaglandins (PGE2) [38-43]. During tumorigenesis, certain genetic mutations in the ras oncogene or Wnt-signaling pathways may also lead to elevated expression of VEGF [44, 45]. Tumor-derived VEGF may also function in an autocrine manner [46]. Receptors for VEGF (e.g., VEGFR1, VEGF2, Nrp1, Nrp2) are expressed on multiple cancer cell lines [47, 48], and there is evidence that VEGF can function as a cell survival factor for tumor cells and vascular endothelial cells within the tumor $[49,50]$.

The idea of vascular progenitor cells derived from bone marrow that incorporate into the tumor vasculature is exciting and controversial [51]. Circulating VEGF as well as other growth factors produced by tumor can mobilize variety of hematopoietic cell populations that express CD45, 


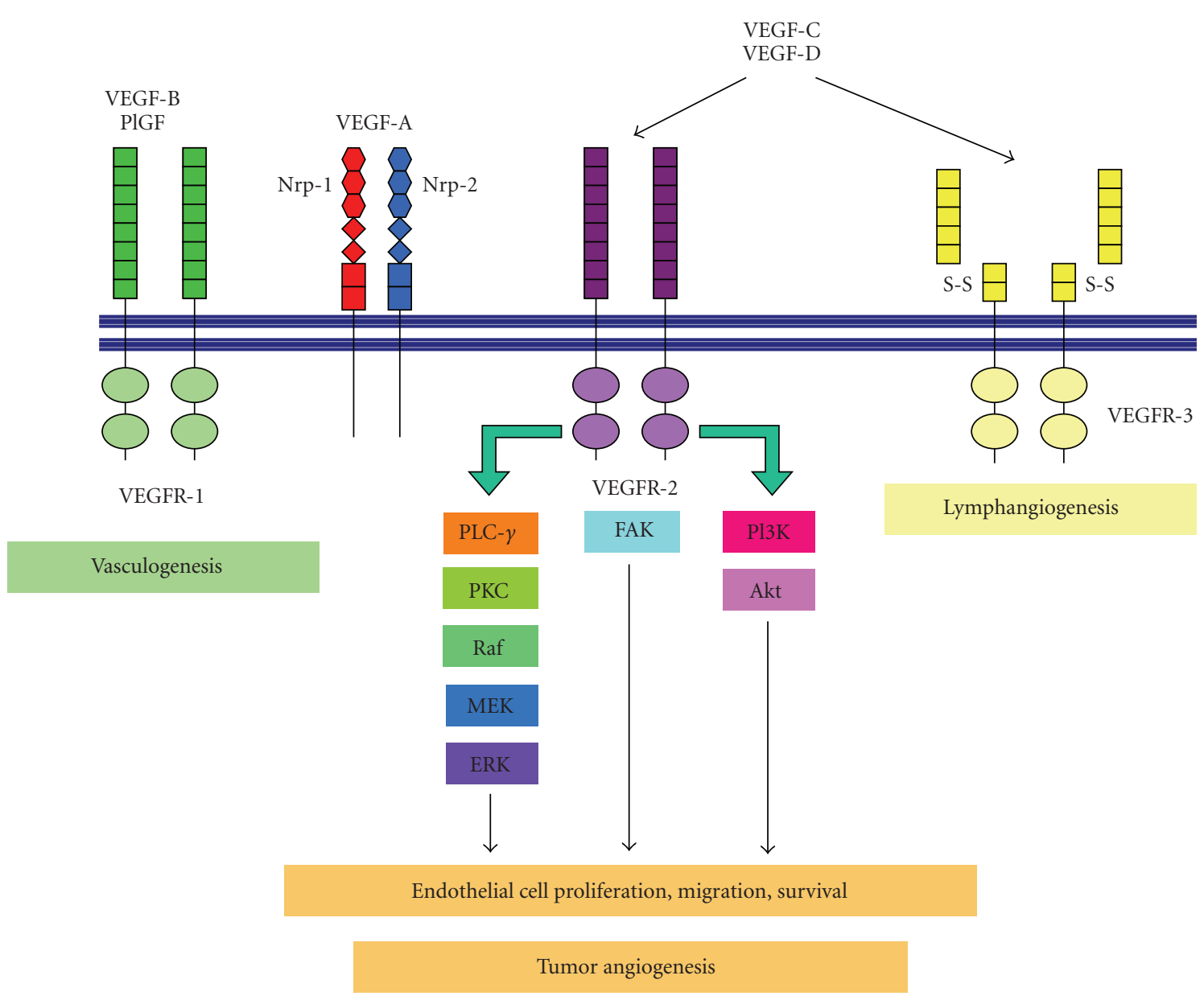

FIGURE 1: VEGF signaling interactions. The VEGF family can bind to VEGFR1, VEGFR2, and VEGFR3 inducing signaling cascades to promote vasculogenesis, angiogenesis, and lymphangiogenesis, respectively.

VEGFR1, VEGFR2, VE-cadherin, tie-2 or CXC chemokine receptor 4 [52-56]. There is a significant discrepancy among the published studies regarding the percentage contribution of bone marrow-derived cells into the formation of tumor vasculature-numbers vary between as high as $50 \%$ to as low as $5 \%[52,57-59]$. However, Robert Kerbel's group observed that after exposure to chemotherapy or vascular disrupting agents (VDAs), there is a significant efflux of circulating bone marrow-derived cells (BMDC) homing to the sites of tumor vasculature $[60,61]$. This phenomenon may have a potent clinical application if confirmed in human studies. Using agents that can block incorporation of BMDCs may contribute to better outcomes of chemotherapy by interfering with tumor angiogenesis.

\section{Clinical Applications of Antiangiogenic Therapy}

The VEGF pathway can be targeted therapeutically at various molecular levels. Currently two major concepts are studied in the clinical setting: blocking VEGF from binding to its extracellular receptors with VEGF antagonists (antibodies, VEGF-Trap) or inhibiting VEGF signaling with tyrosine kinase inhibitors (TKIs) [62]. As previously mentioned, bevacizumab is a humanized, VEGF-neutralizing antibody that was the first antiangiogenic agent approved by the FDA for use in cancer patients. In 2004, a pivotal phase III clinical trial demonstrated a 4.6 months survival benefit of adding bevacizumab to chemotherapy in patients with metastatic colorectal cancer [8]. After the encouraging data from this trial were published, patients with other solid malignancies were enrolled into a multitude of clinical trials that added bevacizumab into the standard treatment of care. However, the results from many of these clinical trials are disappointing. Most patients fail to achieve long-term benefits with bevacizumab plus chemotherapy [63]. Selected groups of patients respond with tumor shrinkage, disease stabilization, or improvements in survival that are counted in months rather than years [64].

A new approach to anti-VEGF therapy currently being evaluated is genetically engineered fusion proteins that function as molecular "traps" for VEGF. Aflibercept (VEGFTrap, Regeneron Pharmaceuticals, Inc.) is a recombinant fusion protein that binds both VEGF and PlGF with high affinity. It is composed of the extracellular domains of VEGFR1 and VEGFR2 that are fused to the Fc region of 
human $\operatorname{IgG}$ [65]. Currently, there are more than 40 ongoing trials (http://clinicaltrials.gov/) that explore this therapy in solid and hematologic malignancies.

Small molecule TKIs with antiangiogenic activity are another important area of active clinical research. Unlike monoclonal antibodies (i.e., bevacizumab) or fusion proteins (i.e., aflibercept), TKIs are small molecules that interfere directly with tyrosine kinase activity (Figure 2 ). Since the intracellular domain targeted by TKIs is structurally similar in many tyrosine kinase receptors, a single TKI usually interferes with the activity of multiple receptors [66]. Sunitinib and sorafenib are multitargeting TKIs that can block activity angiogenic targets such as of VEGFR1, 2, 3, platelet-derived growth factor (PDGF) receptors and c-Kit or RET. After confirmed clinical benefit for sunitinib and sorafenib in selected patient groups $[67,68]$, there are now a variety of ongoing clinical trials recruiting patients from a broad spectrum of solid malignancies (http://www.clinicaltrials.gov/).

\section{Mechanisms of Action of Antiangiogenic Agents}

Various agents that target tumor angiogenesis are currently under investigation in different cancer types in many clinical trials [62]. While some of these agents show more encouraging results than the others, a common clinical problem is the lack of effective tools to monitor tumor response to these novel therapies [69]. The Response Evaluation Criteria in Solid Tumors (RECIST) criteria that are commonly used to monitor tumor response may not be an effective or even accurate measure of response to antiangiogenic agents. As an example, antiangiogenic agents will often enhance the central necrosis of tumors without changing the overall tumor size, which is a central parameter in RECIST evaluation [70].

An area of intense debate is how antiangiogenic agents actually work in terms of combating cancer [71]. According to the Folkman hypothesis, interference with tumor angiogenesis results in either inhibition of new vessel formation or progressive loss of existing vessels supporting tumor growth. An inadequate blood supply caused by a reduction of the vascular network in response to antiangiogenic therapy, slows and eventually prevents tumor growth and causes the tumor to regress to a "state of dormancy", which can be clinically undetectable [7]. Evidence for this paradigm can be found in preclinical studies where fast-growing human tumors are treated with anti-VEGF therapy for long periods of time $[72,73]$.

An alternative explanation for anti-VEGF activity and possibly antiangiogenic agents in general is anchored in the heterogeneity of tumor vasculature. A minority of tumor blood vessels are associated intimately with pericytes and as a result are more functional and stable [74]. These vessels are not as dependent on VEGF stimulation for survival. In contrast, a large proportion of tumor blood vessels are tortuous, leaky, and immature, lacking interactions with pericytes. Furthermore, these vessels are more dependent on survival signals provided by VEGF and other growth factors. When VEGF levels are decreased via therapy these vessels regress, leaving behind a more stable vascular network. There is also compelling evidence that VEGF actively suppresses pericyte recruitment, therefore blocking VEGF activity may also result in the active recruitment of pericytes to remaining blood vessels [75]. As a result, the vasculature that remains in the face of anti-VEGF therapy consists of a higher percentage of pericyte associated blood vessels that are more efficient in function. This process has been termed "normalization" by Jain who hypothesizes that anti-VEGF therapy actually "normalizes" tumor vasculature and transiently improves blood flow within the tumor, thus enhancing the delivery of chemotherapy [76, 77]. Additionally, because stable vessels within the tumor are less leaky, interstitial pressure may decrease and thereby facilitate tissue penetration of chemotherapy. A supportive corollary to this is that antiangiogenic therapy has been shown to increase the efficacy of radiation therapy due to transient improvement in tumor oxygenation as a result of antiangiogenic treatment and vascular normalization $[71,78]$.

\section{Monitoring Clinical Response to Antiangiogenic Therapies}

The majority of noninvasive techniques used to assess the effects of antiangiogenic therapy do not directly visualize tumor blood vessels. Rather surrogate markers for vascular function such as blood flow are used commonly. These techniques rely on the fact that during the course of treatment blood flow within the tumor changes, either increasing due to normalization or decreasing due to diminished blood supply and vessel regression [79-81]. Hemodynamic changes within the tumor vasculature remain the major surrogate markers for majority of these techniques. Clinically relevant imaging techniques include magnetic resonance imaging (MRI), computed tomography (CT), positron emission tomography (PET), and ultrasound (US). Each of these techniques can be used with appropriate contrast media to evaluate hemodynamic function within tissues including solid tumors.

Perfusion dynamic contrast-enhanced (DCE) MRI has been used successfully in both preclinical and clinical models to follow hemodynamic function [82]. DCE-MRI makes use of paramagnetic tracers, mostly consisting of a lowmolecular-weight gadolinium (Gd) and is the standard method for measurement of vascular function in clinical trials of antiangiogenic drugs [83]. Signal enhancement obtained by DCE-MRI depends on tissue perfusion and permeability, contrast concentration, and extravascular space volume [84]. DCE-MRI has been especially useful in clinical studies of patients with liver and brain tumors [85-90], and has been investigated as a possible pharmacodynamic biomarker sorafenib therapy in metastatic renal carcinoma [91].

CT-based perfusion imaging techniques are also used to assess the vascular effects of antiangiogenic treatments $[92,93]$. Although DCE-MRI gives better spatial resolution and is a superior method for brain imaging studies, CT still remains a preferred method for imaging structures within the thorax, abdomen, and pelvis. Thus some clinical studies 

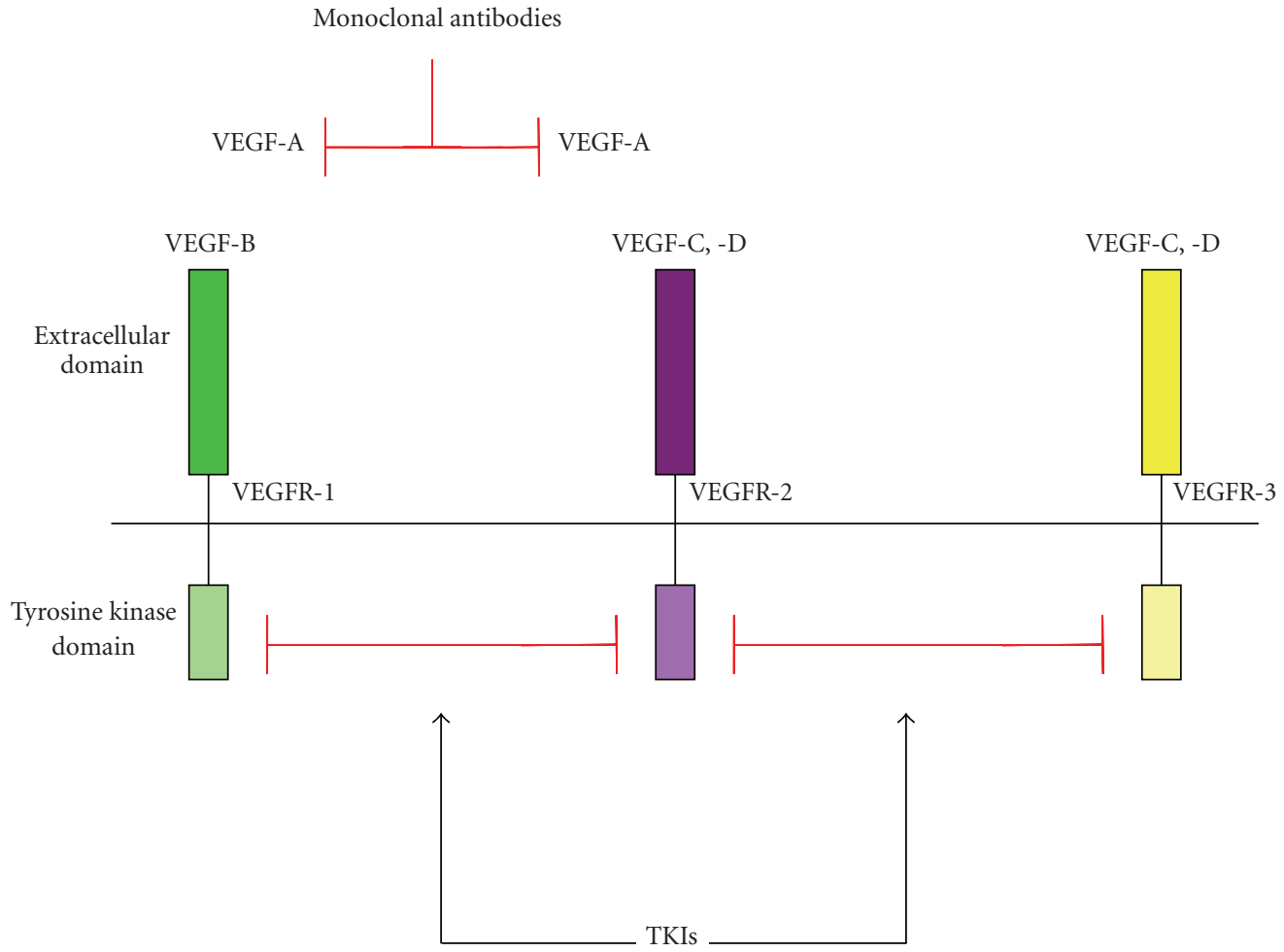

FIGURE 2: Inhibition of VEGF signaling pathways. Several classes of drugs have been developed to combat VEGF-mediated tumor angiogenesis. Monoclonal anti-VEGF antibodies (e.g., bevacizumab) and soluble receptor constructs (e.g., VEGF-Trap) bind to the VEGF and PIGF preventing their interaction and signaling through VEGFR1 and VEGFR2. Tyrosine kinase inhibitors (TKIs) inhibit the intracellular tyrosine kinase activity of VEGF receptors, blocking downstream signaling.

investigating antiangiogenic agents have used perfusion CT rather than DCE-MRI to evaluate tumor blood flow [94-96].

In addition, PET-based imaging techniques are widely used in clinical oncology [97]. PET uses positron-emitting tracers, of which $\mathrm{H}_{2}^{15} \mathrm{O}$ can be used to study tumor blood flow and this method has been used in clinical trials with good results [98]. $\mathrm{H}_{2}^{15} \mathrm{O}$ is a positron-emitting tracer that can diffuse freely into the tissues and its tissue uptake correlates with blood perfusion [99]. Both $\mathrm{H}_{2}^{15} \mathrm{O}$ PET and DCE-MRI are useful for monitoring tumor microvasculature. $\mathrm{H}_{2}^{15} \mathrm{O}$ PET is particularly useful in the assessment of tissue perfusion while DCE-MRI measures also vascular permeability. A major disadvantage of both methods is their limited availability for patients because they require highly skilled and trained staff, that is, typically only available in large radiology or nuclear medicine departments.

Worldwide, ultrasound (US) is one of the most commonly used noninvasive imaging techniques. It provides anatomical information and can also be used to assess physiological function (e.g., blood flow with doppler ultrasound) or to serve as a therapeutic tool (e.g., high frequency ultrasound ablation of the tissue) $[100,101]$. Because blood is only slightly less echogenic than surrounding tissue, US is not very effective for imaging small blood vessels. However, the introduction of US contrast agents expanded the clinical and research applications of US especially in the area of vascular imaging. Microbubbles (MB) are small particles $(1-10 \mu \mathrm{m})$ consisting of a gaseous core and a shell of protein (e.g., albumin) or lipid mixture [102] that can be injected intravenously and are promising US contrast agents. MBs are intravascular tracers that do not extravasate unless there is structural damage to the vessel wall. When injected intravenously, MBs enhance the echogenicity of the blood pool and enable distinction of vascular structures from the surrounding tissue. Within in an ultrasound field $\mathrm{MB}$ resonate in response to the ultrasound wave and can enhance both grey scale images and flow mediated doppler signals. Their high echogenic properties are due to the difference of compressibility of the gaseous core within the $\mathrm{MB}$ and the surrounding blood components and tissue [103]. MB have proven their usefulness in clinical echocardiography, especially in the evaluation of systolic myocardial function, ejection fraction, delineating endocardial border, and myocardial blood flow [104-106]. Imaging metastatic deposits or primary liver tumors (e.g., hepatocellular carcinoma) with contrast US is an example of the clinical application for MB-enhanced US imaging $[107,108]$. The liver is one of the organs, that is, most commonly affected by distant metastases, and early detection of small (subcentimeter) lesions by contrast-enhanced US is of clinical significance [109-111]. Comparative studies of the sensitivity and specificity of PET, CT, DCE-MRI, and MB-enhanced US for detection of tumor perfusion showed 
that contrast US is an effective and correlative method with significant clinical potential [112, 113].

MB behave hemodynamically like red blood cells, circulate freely after injection and are small enough to reach the capillary microcirculation [114]. The idea of targeted imaging using contrast US is based on the selective accumulation of $\mathrm{MB}$ in specific vascular beds that can be reached by US wave and subsequently imaged. MB with an albumincontaining shell can adhere to endothelial cells that are activated by inflammatory cytokines, or activated leukocytes, which enables $\mathrm{MB}$ to be targeted passively to the areas of vascular inflammation [115-117]. MB can be also targeted actively to specific vascular beds by conjugation of targeting moieties (e.g., antibodies or peptides) to the MB shell [118120]. In preclinical studies, $\mathrm{MB}$ have been targeted to various endothelial markers expressed on inflamed or ischemic tissues such as the myocardium or kidney [121-123]. Although tumor endothelial cells are often thought to be genetically normal, work by Hida et al. has demonstrated that mouse endothelial cells harvested from tumor xenografts are aneuploid and have abnormal centromeres [124]. Perhaps related to this cytogenetic abnormality, tumor endothelial cells express specific molecules that are absent or expressed at a much lower levels on endothelium in normal noncancerous tissue. Thus, the tumor vasculature is an attractive subject for imaging with targeted MB and US [125, 126]. The list of potential target molecules selective for tumor vasculature is growing and includes growth factor receptors, integrins, ephrins, endoglin, tumor endothelial markers (TEMs), and markers of cell stress (see Table 1 at supplementary material available at 10.1155/2010/652320).

The development of surrogate markers of pathological angiogenesis to monitor the response of patients to antiangiogenic therapy is of critical importance if antiangiogenic strategies are to be a viable modality for cancer therapy. Contrast US using targeted $\mathrm{MB}$ can be an efficient tool to monitor the expression of surface markers by tumor endothelial cells. This strategy can be used to visualize tumor blood vessels and in addition can follow the expression level of markers that are known to be altered by antiangiogenic therapy. VEGFR2 is a commonly used marker of vascular endothelial cells and has been used by multiple groups as a molecular target for MB. Animal models of angiosarcoma, glioma, and breast cancer showed that VEGFR2 targeted MB enhanced US imaging in evaluation of tumor angiogenesis [127, 128]. Recently, our group evaluated vascular response to antiangiogenic and chemotherapy in mouse models of pancreatic cancer using MB targeted against VEGFR2, the VEGF:VEGFR complex, and endoglin [20]. Using three different formulations of tumor vessel specific MB and US, we were able to noninvasively monitor vascular function of subcutaneous and orthotopic pancreatic tumors in mice. We found that targeting to VEGFR2, endoglin, or the VEGF:VEGFR complex was specific for tumor vasculature as there was no signal enhancement in nontumor tumor tissue. Further, we found that anti-VEGF therapy or treatment with gemcitabine reduced the expression of the molecular targets bound by targeted MB. Our contrast US intensity data correlated with immunohistochemical analysis of tumor samples, providing the first indication that targeted $\mathrm{MB}$ could be used to follow expression of a cell surface target. Additionally, these studies also validated that gemcitabine can effect endothelial cells in tumors. Other groups have since confirmed our findings using targeted MB to image the response of tumor vessels to the therapy [129]. These data and the work of others [130-133] that conclusively demonstrate the utility of contrast US using targeted MB support the clinical evaluation of such strategies as a method for following response to antiangiogenic therapy in cancer patients.

\section{Toxicities of Antiangiogenic Therapies}

VEGF signaling is involved in many normal physiologic processes such as hemostasis, vascular homeostasis and integrity, and the maintenance of endothelial function in kidney glomeruli [134]. Following the introduction of bevacizumab into the clinic, toxic side effects became apparent. The most common side effects of bevacizumab and other antiangiogenic agents are hypertension (3-36\% of patients) and proteinuria (21-64\% of patients) [135]. Although the exact pathophysiological mechanism is not yet fully understood, there is evidence coming from both animal and clinical models, that bevacizumab increases the risk of renal thrombotic microangiopathy [136]. It has been shown in animal models that after binding to VEGF, bevacizumab-VEGF immune complexes can be deposited in the glomerular basement membrane contributing to the development of both proteinuria and hypertension [137]. Bevacizumab has also been shown to increase the incidence of hemorrhagic and thrombotic events in cancer patients. One of the most serious side effects observed in lung cancer patients are hemoptysis and pulmonary hemorrhage. In a phase II clinical trial, NSCLC patients with squamous histology were at a higher risk of developing fatal bleeding, that was most likely related to tumor necrosis and proximity of tumor to the large vessels [138]. Based on this observation bevacizumab is not recommended for squamous NSCLC. In addition, bevacizumab is not recommended for patients with pre-existing conditions that may predispose for either thrombotic or hemorrhagic events (e.g., brain metastases). Bevacizumab can also potentiate the incidence of side effects that are specific to chemotherapy treatment like neutropenia, infections, and thrombocytopenia [139]. There have also been reports of potentially serious toxicities such as nasal septum perforation, reversible posterior leukoencephalopathy syndrome (severe hypertension, cortical blindness, and seizures) or osteonecrosis of the jaw, although these events are very rare [140-142]. TKIs have a unique toxicity profile and are more commonly associated with rash due to blocking EGFR activity and gastrointestinal symptoms like nausea, diarrhea due to the administration of the drug. Hypertension is the predominate toxicity associated with sorafenib and sunitinib treatment due to their antiangiogenic specificities [143]. Endothelial cell production of nitric oxide and prostacyclin is required for mediating vasodilatation and controlling blood pressure. These mediators are stimulated by VEGF-induced VEGFR2 signaling, which is blocked 
by sorafenib and sunitinib treatment. Further, TKIs have recently been reported to increase patient risk of bleeding events due to interruption of VEGF-mediated vascular homeostasis [144].

\section{Future Directions}

Despite the modest survival benefits observed in clinical practice, antiangiogenic therapy remains an attractive concept. Only five years have passed since the first antiangiogenic drug was approved by the FDA for a clinical use. Although we have learned important lessons about this new class of cancer drugs, many questions still remain. The multitude of ongoing clinical trials testing both the new agents and different combinations of agents with already established clinical benefits, may shed light on multiple questions regarding antiangiogenic therapy [145]. Better selection of patients, including the therapeutic schedule of antiangiogenic therapy (i.e., adjuvant versus palliative), monitoring of clinical response, and better toxicity profile of antiangiogenic drugs are among the most important clinical aspects that the ongoing clinical trials will address. In addition, intrinsic and acquired resistance of tumors to antiangiogenic therapies is a growing concern in the clinic, as most patients fail to show sustained benefit with continuous therapy [146]. There are many possible mechanisms of resistance to antiangiogenic therapy that are being actively investigated. One possibility is the activation of alternative molecular pathways resulting in ongoing angiogenesis in response to the presence of a selective inhibitor (e.g., fibroblast growth factor (FGF), interleukin-8, ephrins, angiopoietins, SDF-1 pathway activation, and increased VEGF expression following epidermal growth factor blockade) [147-149]. Also, resistance has been linked to an unresponsiveness of pericyte-covered tumor vessels to antiangiogenic therapies $[150,151]$, and to the hypovascularity and low levels of de novo angiogenesis characteristic of some tumors (e.g., pancreatic cancer) [152]. Although antiangiogenic therapies have entered into clinical practice, we still lack a reliable marker(s) of treatment efficacy. Studies on noninvasive marker(s) such as blood levels of circulating growth factors, cytokines and/or endothelial progenitor cells gave mixed results and are not validated at the present time for a clinical use [153]. Future studies that involve complex proteomicbased analysis may help to find a noninvasive way to not only monitor the effects by also to better select patients who may benefit from antiangiogenic therapies.

\section{Acknowledgment}

This work was supported in part by the Randall Bridwell Lung Cancer Research Grant and the Effie Marie Cain Scholarship in Angiogenesis Research (to R. Brekken).

\section{References}

[1] J. Folkman, "Angiogenesis in cancer, vascular, rheumatoid and other disease," Nature Medicine, vol. 1, no. 1, pp. 27-31, 1995.
[2] N. Ferrara, "VEGF and the quest for tumour angiogenesis factors," Nature Reviews Cancer, vol. 2, no. 10, pp. 795-803, 2002.

[3] M. Narazaki and G. Tosato, "Targeting coagulation to the tumor microvasculature: perspectives and therapeutic implications from preclinical studies," Journal of the National Cancer Institute, vol. 97, no. 10, pp. 705-707, 2005.

[4] B. A. Warren and P. Shubik, "The growth of the blood supply to melanoma transplants in the hamster cheek pouch," Laboratory Investigation, vol. 15, no. 2, pp. 464-478, 1966.

[5] M. Greenblatt and P. Shubi, "Tumor angiogenesis: transfilter diffusion studies in the hamster by the transparent chamber technique," Journal of the National Cancer Institute, vol. 41, no. 1, pp. 111-124, 1968.

[6] J. Folkman, E. Merler, C. Abernathy, and G. Williams, "Isolation of a tumor factor responsible or angiogenesis," Journal of Experimental Medicine, vol. 133, no. 2, pp. 275$288,1971$.

[7] J. Folkman, "Tumor angiogenesis: therapeutic implications," The New England Journal of Medicine, vol. 285, no. 21, pp. 1182-1186, 1971.

[8] H. Hurwitz, L. Fehrenbacher, W. Novotny, et al., "Bevacizumab plus irinotecan, fluorouracil, and leucovorin for metastatic colorectal cancer," The New England Journal of Medicine, vol. 350, no. 23, pp. 2335-2342, 2004.

[9] D. R. Senger, S. J. Galli, A. M. Dvorak, C. A. Perruzzi, V. Susan Harvey, and H. F. Dvorak, "Tumor cells secrete a vascular permeability factor that promotes accumulation of ascites fluid," Science, vol. 219, no. 4587, pp. 983-985, 1983.

[10] D. W. Leung, G. Cachianes, W.-J. Kuang, D. V. Goeddel, and N. Ferrara, "Vascular endothelial growth factor is a secreted angiogenic mitogen," Science, vol. 246, no. 4935, pp. 13061309, 1989.

[11] P. J. Keck, S. D. Hauser, G. Krivi, et al., "Vascular permeability factor, an endothelial cell mitogen related to PDGF," Science, vol. 246, no. 4935, pp. 1309-1312, 1989.

[12] N. Ferrara, H.-P. Gerber, and J. LeCouter, "The biology of VEGF and its receptors," Nature Medicine, vol. 9, no. 6, pp. 669-676, 2003.

[13] H. Takahashi and M. Shibuya, "The vascular endothelial growth factor (VEGF)/VEGF receptor system and its role under physiological and pathological conditions," Clinical Science, vol. 109, no. 3, pp. 227-241, 2005.

[14] J. E. Park, H. H. Chen, J. Winer, K. A. Houck, and N. Ferrara, "Placenta growth factor. Potentiation of vascular endothelial growth factor bioactivity, in vitro and in vivo, and high affinity binding to Flt-1 but not to Flk-1/KDR," Journal of Biological Chemistry, vol. 269, no. 41, pp. 25646-25654, 1994.

[15] B. Olofsson, E. Korpelainen, M. S. Pepper, et al., "Vascular endothelial growth factor B (VEGF-B) binds to VEGF receptor-1 and regulates plasminogen activator activity in endothelial cells," Proceedings of the National Academy of Sciences of the United States of America, vol. 95, no. 20, pp. 11709-11714, 1998.

[16] S. Hiratsuka, O. Minowa, J. Kuno, T. Noda, and M. Shibuya, "Flt-1 lacking the tyrosine kinase domain is sufficient for normal development and angiogenesis in mice," Proceedings of the National Academy of Sciences of the United States of America, vol. 95, no. 16, pp. 9349-9354, 1998.

[17] D. Lyden, K. Hattori, S. Dias, et al., "Impaired recruitment of bone-marrow-derived endothelial and hematopoietic precursor cells blocks tumor angiogenesis and growth," Nature Medicine, vol. 7, no. 11, pp. 1194-1201, 2001. 
[18] G.-H. Fong, J. Rossant, M. Gertsenstein, and M. L. Breitman, "Role of the Flt-1 receptor tyrosine kinase in regulating the assembly of vascular endothelium," Nature, vol. 376, no. 6535, pp. 66-70, 1995.

[19] R. A. Brekken, J. P. Overholser, V. A. Stastny, J. Waltenberger, J. D. Minna, and P. E. Thorpe, "Selective inhibition of vascular endothelial growth factor (VEGF) receptor 2 (KDR/Flk-1) activity by a monoclonal anti-VEGF antibody blocks tumor growth in mice," Cancer Research, vol. 60, no. 18, pp. 5117 5124, 2000.

[20] G. Korpanty, J. G. Carbon, P. A. Grayburn, J. B. Fleming, and R. A. Brekken, "Monitoring response to anticancer therapy by targeting microbubbles to tumor vasculature," Clinical Cancer Research, vol. 13, no. 1, pp. 323-330, 2007.

[21] S. P. Dineen, K. D. Lynn, S. E. Holloway, et al., "Vascular endothelial growth factor receptor 2 mediates macrophage infiltration into orthotopic pancreatic tumors in mice," Cancer Research, vol. 68, no. 11, pp. 4340-4346, 2008.

[22] L. Witte, D. J. Hicklin, Z. Zhu, et al., "Monoclonal antibodies targeting the VEGF receptor-2 (Flk1/KDR) as an anti-angiogenic therapeutic strategy," Cancer and Metastasis Reviews, vol. 17, no. 2, pp. 155-161, 1998.

[23] Y. Izumi, E. Di Tomaso, A. Hooper, et al., "Responses to antiangiogenesis treatment of spontaneous autochthonous tumors and their isografts," Cancer Research, vol. 63, no. 4, pp. 747-751, 2003.

[24] M. Shibuya, "Vascular endothelial growth factor (VEGF)receptor2: its biological functions, major signaling pathway, and specific ligand VEGF-E," Endothelium, vol. 13, no. 2, pp. 63-69, 2006.

[25] K. Holmes, O. L. Roberts, A. M. Thomas, and M. J. Cross, "Vascular endothelial growth factor receptor-2: structure, function, intracellular signalling and therapeutic inhibition," Cellular Signalling, vol. 19, no. 10, pp. 2003-2012, 2007.

[26] N. Ferrara, "Vascular endothelial growth factor: basic science and clinical progress," Endocrine Reviews, vol. 25, no. 4, pp. 581-611, 2004.

[27] K. Paavonen, P. Puolakkainen, L. Jussila, T. Jahkola, and K. Alitalo, "Vascular endothelial growth factor receptor-3 in lymphangiogenesis in wound healing," American Journal of Pathology, vol. 156, no. 5, pp. 1499-1504, 2000.

[28] Y. He, I. Rajantie, K. Pajusola, et al., "Vascular endothelial cell growth factor receptor 3-mediated activation of lymphatic endothelium is crucial for tumor cell entry and spread via lymphatic vessels," Cancer Research, vol. 65, no. 11, pp. 47394746, 2005.

[29] Y. He, K.-I. Kozaki, T. Karpanen, et al., "Suppression of tumor lymphangiogenesis and lymph node metastasis by blocking vascular endothelial growth factor receptor 3 signaling," Journal of the National Cancer Institute, vol. 94, no. 11, pp. 819-825, 2002.

[30] G. Neufeld, T. Cohen, N. Shraga, T. Lange, O. Kessler, and Y. Herzog, "The neuropilins: multifunctional semaphorin and VEGF receptors that modulate axon guidance and angiogenesis," Trends in Cardiovascular Medicine, vol. 12, no. 1, pp. 13-19, 2002.

[31] S. Soker, H. Fidder, G. Neufeld, and M. Klagsbrun, "Characterization of novel vascular endothelial growth factor (VEGF) receptors on tumor cells that bind VEGF165 via its exon 7-encoded domain," Journal of Biological Chemistry, vol. 271, no. 10, pp. 5761-5767, 1996.

[32] S. Soker, S. Takashima, H. Q. Miao, G. Neufeld, and M. Klagsbrun, "Neuropilin-1 is expressed by endothelial and tumor cells as an isoform- specific receptor for vascular endothelial growth factor," Cell, vol. 92, no. 6, pp. 735-745, 1998.

[33] M. Safran and W. G. Kaelin Jr., "HIF hydroxylation and the mammalian oxygen-sensing pathway," Journal of Clinical Investigation, vol. 111, no. 6, pp. 779-783, 2003.

[34] G. L. Wang and G. L. Semenza, "Purification and characterization of hypoxia-inducible factor 1," Journal of Biological Chemistry, vol. 270, no. 3, pp. 1230-1237, 1995.

[35] G. L. Wang, B.-H. Jiang, E. A. Rue, and G. L. Semenza, "Hypoxia-inducible factor 1 is a basic-helix-loop-helix-PAS heterodimer regulated by cellular $\mathrm{O}_{2}$ tension," Proceedings of the National Academy of Sciences of the United States of America, vol. 92, no. 12, pp. 5510-5514, 1995.

[36] G. L. Semenza, "HIF-1, $\mathrm{O}_{2}$, and the 3 PHDs: how animal cells signal hypoxia to the nucleus," Cell, vol. 107, no. 1, pp. 1-3, 2001.

[37] A. P. Levy, N. S. Levy, S. Wegner, and M. A. Goldberg, "Transcriptional regulation of the rat vascular endothelial growth factor gene by hypoxia," Journal of Biological Chemistry, vol. 270, no. 22, pp. 13333-13340, 1995.

[38] T. Cohen, D. Nahari, L. W. Cerem, G. Neufeld, and B.Z. Levin, "Interleukin 6 induces the expression of vascular endothelial growth factor," Journal of Biological Chemistry, vol. 271, no. 2, pp. 736-741, 1996.

[39] S. Frank, G. Hubner, G. Breier, M. T. Longaker, D. G. Greenhalgh, and S. Werner, "Regulation of vascular endothelial growth factor expression in cultured keratinocytes. Implications for normal and impaired wound healing," Journal of Biological Chemistry, vol. 270, no. 21, pp. 12607-12613, 1995.

[40] L. Pertovaara, A. Kaipainen, T. Mustonen, et al., "Vascular endothelial growth factor is induced in response to transforming growth factor- $\beta$ in fibroblastic and epithelial cells," Journal of Biological Chemistry, vol. 269, no. 9, pp. 62716274, 1994.

[41] R. S. Warren, H. Yuan, M. R. Matli, N. Ferrara, and D. B. Donner, "Induction of vascular endothelial growth factor by insulin-like growth factor 1 in colorectal carcinoma," Journal of Biological Chemistry, vol. 271, no. 46, pp. 29483-29488, 1996.

[42] P. Ben-Av, L. J. Crofford, R. L. Wilder, and T. Hla, "Induction of vascular endothelial growth factor expression in synovial fibroblasts by prostaglandin E and interleukin-1: a potential mechanism for inflammatory angiogenesis," FEBS Letters, vol. 372, no. 1, pp. 83-87, 1995.

[43] Y.-Q. Li, K.-S. Tao, N. Ren, and Y.-H. Wang, "Effect of c-fos antisense probe on prostaglandin E2-induced upregulation of vascular endothelial growth factor mRNA in human liver cancer cells," World Journal of Gastroenterology, vol. 11, no. 28, pp. 4427-4430, 2005.

[44] S. Grugel, G. Finkenzeller, K. Weindel, B. Barleon, and D. Marme, "Both v-Ha-Ras and v-Raf stimulate expression of the vascular endothelial growth factor in NIH $3 \mathrm{~T} 3$ cells," Journal of Biological Chemistry, vol. 270, no. 43, pp. 2591525919, 1995.

[45] F. Okada, J. W. Rak, B. St. Croix, et al., "Impact of oncogenes in tumor angiogenesis: mutant K-ras up-regulation of vascular endothelial growth factor/vascular permeability factor is necessary, but not sufficient for tumorigenicity of human colorectal carcinoma cells," Proceedings of the National Academy of Sciences of the United States of America, vol. 95, no. 7, pp. 3609-3614, 1998.

[46] J. S. Wey, O. Stoeltzing, and L. M. Ellis, "Vascular endothelial growth factor receptors: expression and function in solid 
tumors," Clinical Advances in Hematology \& Oncology, vol. 2, no. 1, pp. 37-45, 2004.

[47] M. Decaussin, H. Sartelet, C. Robert, et al., "Expression of vascular endothelial growth factor (VEGF) and its two receptors (VEGF-R1-Flt1 and VEGF-R2-Flk1/KDR) in nonsmall cell lung carcinomas (NSCLCs): correlation with angiogenesis and survival," Journal of Pathology, vol. 188, no. 4, pp. 369-377, 1999.

[48] S. Lantuéjoul, B. Constantin, H. Drabkin, C. Brambilla, J. Roche, and E. Brambilla, "Expression of VEGF, semaphorin SEMA3F, and their common receptors neuropilins NP1 and NP2 in preinvasive bronchial lesions, lung tumours, and cell lines," Journal of Pathology, vol. 200, no. 3, pp. 336-347, 2003.

[49] E. Castro-Rivera, S. Ran, P. Thorpe, and J. D. Minna, "Semaphorin 3B (SEMA3B) induces apoptosis in lung and breast cancer, whereas VEGF165 antagonizes this effect," Proceedings of the National Academy of Sciences of the United States of America, vol. 101, no. 31, pp. 11432-11437, 2004.

[50] P. Nasarre, B. Constantin, L. Rouhaud, et al., "Semaphorin SEMA3F and VEGF have opposing effects on cell attachment and spreading," Neoplasia, vol. 5, no. 1, pp. 83-92, 2003.

[51] F. Bertolini, Y. Shaked, P. Mancuso, and R. S. Kerbel, "The multifaceted circulating endothelial cell in cancer: towards marker and target identification," Nature Reviews Cancer, vol. 6, no. 11, pp. 835-845, 2006.

[52] T. Okazaki, S. Ebihara, M. Asada, A. Kanda, H. Sasaki, and M. Yamaya, "Granulocyte colony-stimulating factor promotes tumor angiogenesis via increasing circulating endothelial progenitor cells and Gr1+CD11b+ cells in cancer animal models," International Immunology, vol. 18, no. 1, pp. 1-9, 2006.

[53] M. De Palma, M. A. Venneri, R. Galli, et al., "Tie2 identifies a hematopoietic lineage of proangiogenic monocytes required for tumor vessel formation and a mesenchymal population of pericyte progenitors," Cancer Cell, vol. 8, no. 3, pp. 211-226, 2005.

[54] M. A. Venneri, M. De Palma, M. Ponzoni, et al., "Identification of proangiogenic TIE2-expressing monocytes (TEMs) in human peripheral blood and cancer," Blood, vol. 109, no. 12, pp. 5276-5285, 2007.

[55] J. R. Conejo-Garcia, R. J. Buckanovich, F. Benencia, et al., "Vascular leukocytes contribute to tumor vascularization," Blood, vol. 105, no. 2, pp. 679-681, 2005.

[56] M. Grunewald, I. Avraham, Y. Dor, et al., "VEGF-induced adult neovascularization: recruitment, retention, and role of accessory cells," Cell, vol. 124, no. 1, pp. 175-189, 2006.

[57] B. A. Peters, L. A. Diaz Jr., K. Polyak, et al., "Contribution of bone marrow-derived endothelial cells to human tumor vasculature," Nature Medicine, vol. 11, no. 3, pp. 261-262, 2005.

[58] M. Garcia-Barros, F. Paris, C. Cordon-Cardo, et al., "Tumor response to radiotherapy regulated by endothelial cell apoptosis," Science, vol. 300, no. 5622, pp. 1155-1159, 2003.

[59] H. Spring, T. Schüler, B. Arnold, G. J. Hämmerling, and R. Ganss, "Chemokines direct endothelial progenitors into tumor neovessels," Proceedings of the National Academy of Sciences of the United States of America, vol. 102, no. 50, pp. 18111-18116, 2005.

[60] Y. Shaked, A. Ciarrocchi, M. Franco, et al., "Therapy-induced acute recruitment of circulating endothelial progenitor cells to tumors," Science, vol. 313, no. 5794, pp. 1785-1787, 2006.

[61] D. W. Siemann, D. J. Chaplin, and M. R. Horsman, "Vasculartargeting therapies for treatment of malignant disease," Cancer, vol. 100, no. 12, pp. 2491-2499, 2004.
[62] N. Ferrara and R. S. Kerbel, "Angiogenesis as a therapeutic target,” Nature, vol. 438, no. 7070, pp. 967-974, 2005.

[63] R. K. Jain, D. G. Duda, J. W. Clark, and J. S. Loeffler, "Lessons from phase III clinical trials on anti-VEGF therapy for cancer," Nature Clinical Practice Oncology, vol. 3, no. 1, pp. 24-40, 2006.

[64] M. A. Medina, R. Munoz-Chapuli, and A. R. Quesada, "Challenges of antiangiogenic cancer therapy: trials and errors, and renewed hope," Journal of Cellular and Molecular Medicine, vol. 11, no. 3, pp. 374-382, 2007.

[65] "Aflibercept: AVE 0005, AVE 005, AVE0005, VEGF Trapregeneron, VEGF Trap (R1R2), VEGF Trap-eye," Drugs in $R$ and D, vol. 9, no. 4, pp. 261-269, 2008.

[66] D. S. Krause and R. A. Van Etten, "Tyrosine kinases as targets for cancer therapy," The New England Journal of Medicine, vol. 353, no. 2, pp. 172-187, 2005.

[67] R. J. Motzer, T. E. Hutson, P. Tomczak, et al., "Sunitinib versus interferon alfa in metastatic renal-cell carcinoma," The New England Journal of Medicine, vol. 356, no. 2, pp. 115-124, 2007.

[68] J. M. Llovet, S. Ricci, V. Mazzaferro, et al., "Sorafenib in advanced hepatocellular carcinoma," The New England Journal of Medicine, vol. 359, no. 4, pp. 378-390, 2008.

[69] A. M. Jubb, A. J. Oates, S. Holden, and H. Koeppen, "Predicting benefit from anti-angiogenic agents in malignancy," Nature Reviews Cancer, vol. 6, no. 8, pp. 626-635, 2006.

[70] C. C. Jaffe, "Measures of response: RECIST, WHO, and new alternatives," Journal of Clinical Oncology, vol. 24, no. 20, pp. 3245-3251, 2006.

[71] D. G. Duda, R. K. Jain, and C. G. Willett, "Antiangiogenics: the potential role of integrating this novel treatment modality with chemoradiation for solid cancers," Journal of Clinical Oncology, vol. 25, no. 26, pp. 4033-4042, 2007.

[72] L. A. Akslen and G. N. Naumov, "Tumor dormancy-from basic mechanisms to clinical practice," APMIS, vol. 116, no. 7-8, pp. 545-547, 2008.

[73] G. N. Naumov, J. Folkman, O. Straume, and L. A. Akslen, "Tumor-vascular interactions and tumor dormancy," APMIS, vol. 116, no. 7-8, pp. 569-585, 2008.

[74] P. Carmeliet, "Angiogenesis in life, disease and medicine," Nature, vol. 438, no. 7070, pp. 932-936, 2005.

[75] J. I. Greenberg, D. J. Shields, S. G. Barillas, et al., "A role for VEGF as a negative regulator of pericyte function and vessel maturation," Nature, vol. 456, no. 7223, pp. 809-814, 2008.

[76] R. K. Jain, "Normalizing tumor vasculature with antiangiogenic therapy: a new paradigm for combination therapy," Nature Medicine, vol. 7, no. 9, pp. 987-989, 2001.

[77] R. K. Jain, "Normalization of tumor vasculature: an emerging concept in antiangiogenic therapy," Science, vol. 307, no. 5706, pp. 58-62, 2005.

[78] R. P. M. Dings, M. Loren, H. Heun, et al., "Scheduling of radiation with angiogenesis inhibitors anginex and avastin improves therapeutic outcome via vessel normalization," Clinical Cancer Research, vol. 13, no. 11, pp. 3395-3402, 2007.

[79] D. M. McDonald and P. L. Choyke, "Imaging of angiogenesis: from microscope to clinic," Nature Medicine, vol. 9, no. 6, pp. 713-725, 2003.

[80] J. M. Provenzale, "Imaging of angiogenesis: clinical techniques and novel imaging methods," American Journal of Roentgenology, vol. 188, no. 1, pp. 11-23, 2007.

[81] Y. Shaked, F. Bertolini, S. Man, et al., "Genetic heterogeneity of the vasculogenic phenotype parallels angiogenesis: implications for cellular surrogate marker analysis of antiangiogenesis," Cancer Cell, vol. 7, no. 1, pp. 101-111, 2005. 
[82] A. R. Padhani and M. O. Leach, "Antivascular cancer treatments: functional assessments by dynamic contrastenhanced magnetic resonance imaging," Abdominal Imaging, vol. 30, no. 3, pp. 324-341, 2005.

[83] T. Barrett, M. Brechbiel, M. Bernardo, and P. L. Choyke, "MRI of tumor angiogenesis," Journal of Magnetic Resonance Imaging, vol. 26, no. 2, pp. 235-249, 2007.

[84] P. S. Tofts, G. Brix, D. L. Buckley, et al., "Estimating kinetic parameters from dynamic contrast-enhanced T1- weighted MRI of a diffusable tracer: standardized quantities and symbols," Journal of Magnetic Resonance Imaging, vol. 10, no. 3, pp. 223-232, 1999.

[85] B. Morgan, A. L. Thomas, J. Drevs, et al., "Dynamic contrastenhanced magnetic resonance imaging as a biomarker for the pharmacological response of PTK787/ZK 222584, an inhibitor of the vascular endothelial growth factor receptor tyrosine kinases, in patients with advanced colorectal cancer and liver metastases: results from two phase I studies," Journal of Clinical Oncology, vol. 21, no. 21, pp. 3955-3964, 2003.

[86] A. Gossmann, T. H. Helbich, N. Kuriyama, et al., "Dynamic contrast-enhanced magnetic resonance imaging as a surrogate marker of tumor response to anti-angiogenic therapy in a xenograft model of glioblastoma multiforme," Journal of Magnetic Resonance Imaging, vol. 15, no. 3, pp. 233-240, 2002.

[87] M. O. Leach, K. M. Brindle, J. L. Evelhoch, et al., "Assessment of antiangiogenic and antivascular therapeutics using MRI: recommendations for appropriate methodology for clinical trials," British Journal of Radiology, vol. 76, no. 1, pp. S87S91, 2003.

[88] J. C. Miller, H. H. Pien, D. Sahani, A. G. Sorensen, and J. H. Thrall, "Imaging angiogenesis: application and potential for drug development," Journal of the National Cancer Institute, vol. 97, no. 3, pp. 172-187, 2005.

[89] M. A. Rosen and M. D. Schnall, "Dynamic contrast-enhanced magnetic resonance imaging for assessing tumor vascularity and vascular effects of targeted therapies in renal cell carcinoma," Clinical Cancer Research, vol. 13, no. 2, part 2, pp. 770s-776s, 2007.

[90] C. G. Willett, Y. Boucher, E. Di Tomaso, et al., "Direct evidence that the VEGF-specific antibody bevacizumab has antivascular effects in human rectal cancer," Nature Medicine, vol. 10, no. 2, pp. 145-147, 2004.

[91] O. M. Hahn, C. Yang, M. Medved, et al., "Dynamic contrastenhanced magnetic resonance imaging pharmacodynamic biomarker study of sorafenib in metastatic renal carcinoma," Journal of Clinical Oncology, vol. 26, no. 28, pp. 4572-4578, 2008.

[92] A. X. Zhu, N. S. Holalkere, A. Muzikansky, K. Horgan, and D. V. Sahani, "Early antiangiogenic activity of bevacizumab evaluated by computed tomography perfusion scan in patients with advanced hepatocellular carcinoma," Oncologist, vol. 13, no. 2, pp. 120-125, 2008.

[93] A. R. Broumas, R. E. Pollard, S. H. Bloch, E. R. Wisner, S. Griffey, and K. W. Ferrara, "Contrast-enhanced computed tomography and ultrasound for the evaluation of tumor blood flow," Investigative Radiology, vol. 40, no. 3, pp. 134147, 2005.

[94] P. E. Dugdale, K. A. Miles, I. Bunce, B. B. Kelley, and D. A. C. Leggett, "CT measurement of perfusion and permeability within lymphoma masses and its ability to assess grade, activity, and chemotherapeutic response," Journal of Computer Assisted Tomography, vol. 23, no. 4, pp. 540-547, 1999.
[95] R. E. Pollard, T. C. Garcia, S. M. Stieger, K. W. Ferrara, A. R. Sadlowski, and E. R. Wisner, "Quantitative evaluation of perfusion and permeability of peripheral tumors using contrastenhanced computed tomography," Investigative Radiology, vol. 39, no. 6, pp. 340-349, 2004.

[96] Y. Tsushima, S. Funabasama, J. Aoki, S. Sanada, and K. Endo, "Quantitative perfusion map of malignant liver tumors, created from dynamic computed tomography data," Academic Radiology, vol. 11, no. 2, pp. 215-223, 2004.

[97] F. Castell and G. J. R. Cook, "Quantitative techniques in 18FDG PET scanning in oncology," British Journal of Cancer, vol. 98, no. 10, pp. 1597-1601, 2008.

[98] M. A. Lodge, R. E. Carson, J. A. Carrasquillo, M. Whatley, S. K. Libutti, and S. L. Bacharach, "Parametric images of blood flow in oncology PET studies using [15O]water," Journal of Nuclear Medicine, vol. 41, no. 11, pp. 1784-1792, 2000.

[99] A. J. De Langen, V. E. M. Van Den Boogaart, J. T. Marcus, and M. Lubberink, "Use of H215O-PET and DCE-MRI to measure tumor blood flow," Oncologist, vol. 13, no. 6, pp. 631-644, 2008.

[100] D. L. Franklin, W. Schlegel, and R. F. Rushmer, "Blood flow measured by Doppler frequency shift of back-scattered ultrasound," Science, vol. 134, no. 3478, pp. 564-565, 1961.

[101] W. J. Fry, et al., "Production of focal destructive lesions in the central nervous system with ultrasound," Journal of Neurosurgery, vol. 11, no. 5, pp. 417-418, 1954.

[102] J.-M. Correas, L. Bridal, A. Lesavre, A. Méjean, M. Claudon, and O. Hélénon, "Ultrasound contrast agents: properties, principles of action, tolerance, and artifacts," European Radiology, vol. 11, no. 8, pp. 1316-1328, 2001.

[103] K. E. Morgan, "Experimental and theoretical evaluation of microbubble behavior: effect of transmitted phase and bubble size," IEEE Transactions on Ultrasonics, Ferroelectrics, and Frequency Control, vol. 47, no. 6, pp. 1494-1509, 2000.

[104] J. Cwajg, et al., "Detection of angiographically significant coronary artery disease with accelerated intermittent imaging after intravenous administration of ultrasound contrast material," American Heart Journal, vol. 139, no. 4, pp. 675683, 2000.

[105] S.-C. Cheng, T. C. Dy, and S. B. Feinstein, "Contrast echocardiography: review and future directions," American Journal of Cardiology, vol. 81, no. 12 A, pp. 41G-48G, 1998.

[106] J. L. Cohen, J. Cheirif, D. S. Segar, et al., "Improved left ventricular endocardial border delineation and opacification with OPTISON (FS069), a new echocardiographic contrast agent: results of a phase III multicenter trial," Journal of the American College of Cardiology, vol. 32, no. 3, pp. 746-752, 1998.

[107] M. Krix, "Quantification of enhancement in contrast ultrasound: a tool for monitoring of therapies in liver metastases," European Radiology, Supplement, vol. 15, no. 5, pp. E104E108, 2005.

[108] M. Krix, et al., "Monitoring of liver metastases after stereotactic radiotherapy using low-MI contrast-enhanced ultrasound-initial results," European Radiology, vol. 15, no. 4, pp. 677-684, 2005.

[109] T. K. Kim, B. I. Choi, J. K. Han, H.-S. Hong, S. H. Park, and S. G. Moon, "Hepatic tumors: contrast agent-enhancement patterns with pulse-inversion harmonic US," Radiology, vol. 216, no. 2, pp. 411-417, 2000.

[110] F. Forsberg, B. B. Goldberg, J.-B. Liu, D. A. Merton, N. M. Rawool, and W. T. Shi, "Tissue-specific US contrast agent for evaluation of hepatic and splenic parenchyma," Radiology, vol. 210, no. 1, pp. 125-132, 1999. 
[111] C. J. Harvey, M. J. K. Blomley, R. J. Eckersley, R. A. Heckemann, J. Butler-Barnes, and D. O. Cosgrove, "Pulseinversion mode imaging of liver specific microbubbles: improved detection of subcentimetre metastases," Lancet, vol. 355, no. 9206, pp. 807-808, 2000.

[112] K. J. Niermann, A. C. Fleischer, J. Huamani, et al., "Measuring tumor perfusion in control and treated murine tumors: correlation of microbubble contrast-enhanced sonography to dynamic contrast-enhanced magnetic resonance imaging and fluorodeoxyglucose positron emission tomography," Journal of Ultrasound in Medicine, vol. 26, no. 6, pp. 749-756, 2007.

[113] T. E. Yankeelov, et al., "Correlation between estimates of tumor perfusion from microbubble contrast-enhanced sonography and dynamic contrast-enhanced magnetic resonance imaging," Journal of Ultrasound in Medicine, vol. 25, no. 4, pp. 487-497, 2006.

[114] S. Ismail, et al., "Relation between air-filled albumin microbubble and red blood cell rheology in the human myocardium. Influence of echocardiographic systems and chest wall attenuation," Circulation, vol. 94 , no. 3, pp. 445451, 1996.

[115] F. S. Villanueva, R. J. Jankowski, C. Manaugh, and W. R. Wagner, "Albumin microbubble adherence to human coronary endotheliumml: implications for assessment of endothelial function using myocardial contrast echocardiography," Journal of the American College of Cardiology, vol. 30, no. 3, pp. 689-693, 1997.

[116] J. R. Lindner, M. P. Coggins, S. Kaul, A. L. Klibanov, G. H. Brandenburger, and K. Ley, "Microbubble persistence in the microcirculation during ischemia/reperfusion and inflammation is caused by integrin- and complement- mediated adherence to activated leukocytes," Circulation, vol. 101, no. 6, pp. 668-675, 2000.

[117] J. R. Lindner, P. A. Dayton, M. P. Coggins, et al., "Noninvasive imaging of inflammation by ultrasound detection of Phagocytosed microbubbles," Circulation, vol. 102, no. 5, pp. 531-538, 2000.

[118] P. A. Dayton and K. W. Ferrara, "Targeted imaging using ultrasound," Journal of Magnetic Resonance Imaging, vol. 16, no. 4, pp. 362-377, 2002.

[119] G. Korpanty, P. A. Grayburn, R. V. Shohet, and R. A. Brekken, "Targeting vascular endothelium with avidin microbubbles," Ultrasound in Medicine and Biology, vol. 31, no. 9, pp. 12791283, 2005.

[120] G. M. Lanza and S. A. Wickline, "Targeted ultrasonic contrast agents for molecular imaging and therapy," Progress in Cardiovascular Diseases, vol. 44, no. 1, pp. 13-31, 2001.

[121] J. R. Lindner, J. Song, J. Christiansen, A. L. Klibanov, F. Xu, and K. Ley, "Ultrasound assessment of inflammation and renal tissue injury with microbubbles targeted to P-selectin," Circulation, vol. 104, no. 17, pp. 2107-2112, 2001.

[122] F. S. Villanueva, R. J. Jankowski, S. Klibanov, et al., "Microbubbles targeted to intercellular adhesion molecule-1 bind to activated coronary artery endothelial cells," Circulation, vol. 98, no. 1, pp. 1-5, 1998.

[123] F. S. Villanueva and W. R. Wagner, "Ultrasound molecular imaging of cardiovascular disease," Nature Clinical Practice Cardiovascular Medicine, vol. 5, no. 2, pp. S26-S32, 2008.

[124] K. Hida, Y. Hida, D. N. Amin, et al., "Tumor-associated endothelial cells with cytogenetic abnormalities," Cancer Research, vol. 64, no. 22, pp. 8249-8255, 2004.
[125] B. St. Croix, C. Rago, V. Velculescu, et al., "Genes expressed in human tumor endothelium," Science, vol. 289, no. 5482, pp. 1197-1202, 2000.

[126] A. Eberhard, S. Kahlert, V. Goede, B. Hemmerlein, K. H. Plate, and H. G. Augustin, "Heterogeneity of angiogenesis and blood vessel maturation in human tumors: implications for antiangiogenic tumor therapies," Cancer Research, vol. 60, no. 5, pp. 1388-1393, 2000.

[127] D. J. Lee, et al., "Relationship between retention of a vascular endothelial growth factor receptor 2 (VEGFR2)-targeted ultrasonographic contrast agent and the level of VEGFR2 expression in an in vivo breast cancer model," Journal of Ultrasound in Medicine, vol. 27, no. 6, pp. 855-866, 2008.

[128] A. Lyshchik, A. C. Fleischer, J. Huamani, D. E. Hallahan, M. Brissova, and J. C. Gore, "Molecular imaging of vascular endothelial growth factor receptor 2 expression using targeted contrast-enhanced high-frequency ultrasonography," Journal of Ultrasound in Medicine, vol. 26, no. 11, pp. 15751586, 2007.

[129] M. Palmowski, J. Huppert, G. Ladewig, et al., "Molecular profiling of angiogenesis with targeted ultrasound imaging: early assessment of antiangiogenic therapy effects," Molecular Cancer Therapeutics, vol. 7, no. 1, pp. 101-109, 2008.

[130] H. Leong-Poi, "Molecular imaging using contrast-enhanced ultrasound: evaluation of angiogenesis and cell therapy," Cardiovascular Research, vol. 84, no. 2, pp. 190-200, 2009.

[131] M. A. Kuliszewski, H. Fuj II, C. Liao, et al., "Molecular imaging of endothelial progenitor cell engraftment using contrast-enhanced ultrasound and targeted microbubbles," Cardiovascular Research, vol. 83, no. 4, pp. 653-662, 2009.

[132] J. K. Willmann, Z. Cheng, C. Davis, et al., "Targeted microbubbles for imaging tumor angiogenesis: assessment of whole-body biodistribution with dynamic micro-pet in Mice," Radiology, vol. 249, no. 1, pp. 212-219, 2008.

[133] J. K. Willmann, A. M. Lutz, R. Paulmurugan, et al., "Dualtargeted contrast agent for US assessment of tumor angiogenesis in vivo," Radiology, vol. 248, no. 3, pp. 936-944, 2008.

[134] H. M. W. Verheul and H. M. Pinedo, "Possible molecular mechanisms involved in the toxicity of angiogenesis inhibition," Nature Reviews Cancer, vol. 7, no. 6, pp. 475-485, 2007.

[135] X. Zhu, S. Wu, W. L. Dahut, and C. R. Parikh, "Risks of proteinuria and hypertension with bevacizumab, an antibody against vascular endothelial growth factor: systematic review and meta-analysis," American Journal of Kidney Diseases, vol. 49, no. 2, pp. 186-193, 2007.

[136] V. Eremina, J. A. Jefferson, J. Kowalewska, et al., "VEGF inhibition and renal thrombotic microangiopathy," The New England Journal of Medicine, vol. 358, no. 11, pp. 1129-1136, 2008.

[137] J. S. Rudge, et al., "Inaugural article: VEGF Trap complex formation measures production rates of VEGF, providing a biomarker for predicting efficacious angiogenic blockade," Proceedings of the National Academy of Sciences of USA, vol. 104, no. 47, pp. 18363-18370, 2007.

[138] R. S. Herbst and A. B. Sandler, "Non-small cell lung cancer and antiangiogenic therapy: what can be expected of bevacizumab?" Oncologist, vol. 9, no. 1, pp. 19-26, 2004.

[139] A. Sandler, R. Gray, M. C. Perry, et al., "Paclitaxel-carboplatin alone or with bevacizumab for non-small-cell lung cancer," The New England Journal of Medicine, vol. 355, no. 24, pp. 2542-2550, 2006.

[140] T. A. Traina, L. Norton, K. Drucker, and B. Singh, "Nasal septum perforation in a bevacizumab-treated patient with 
metastatic breast cancer," Oncologist, vol. 11, no. 10, pp. 1070-1071, 2006.

[141] C. Ozcan, S. J. Wong, and P. Hari, "Reversible posterior leukoencephalopathy syndrome and bevacizumab," The New England Journal of Medicine, vol. 354, no. 9, pp. 981-982, 2006.

[142] C. L. Estilo, M. Fornier, A. Farooki, D. Carlson, G. Bohle I II, and J. M. Huryn, "Osteonecrosis of the jaw related to bevacizumab," Journal of Clinical Oncology, vol. 26, no. 24, pp. 4037-4038, 2008.

[143] J. M. Roodhart, M. H. Langenberg, E. Witteveen, and E. E. Voest, "The molecular basis of class side effects due to treatment with inhibitors of the VEGF/VEGFR pathway," Current Clinical Pharmacology, vol. 3, no. 2, pp. 132-143, 2008.

[144] Y. Je, F. A. Schutz, and T. K. Choueiri, "Risk of bleeding with vascular endothelial growth factor receptor tyrosine-kinase inhibitors sunitinib and sorafenib: a systematic review and meta-analysis of clinical trials," The Lancet Oncology, vol. 10, no. 10, pp. 967-974, 2009.

[145] V. Brower, "Antiangiogenesis research is booming, as questions and studies proliferate," Journal of the National Cancer Institute, vol. 101, no. 11, pp. 780-781, 2009.

[146] G. Bergers and D. Hanahan, "Modes of resistance to antiangiogenic therapy," Nature Reviews Cancer, vol. 8, no. 8, pp. 592-603, 2008.

[147] T. T. Batchelor, A. G. Sorensen, E. di Tomaso, et al., "AZD2171, a pan-VEGF receptor tyrosine kinase inhibitor, normalizes tumor vasculature and alleviates edema in glioblastoma patients," Cancer Cell, vol. 11, no. 1, pp. 83-95, 2007.

[148] O. Casanovas, D. J. Hicklin, G. Bergers, and D. Hanahan, "Drug resistance by evasion of antiangiogenic targeting of VEGF signaling in late-stage pancreatic islet tumors," Cancer Cell, vol. 8, no. 4, pp. 299-309, 2005.

[149] Y. Mizukami, W.-S. Jo, E.-M. Duerr, et al., "Induction of interleukin-8 preserves the angiogenic response in HIF-1 $\alpha$ deficient colon cancer cells," Nature Medicine, vol. 11, no. 9, pp. 992-997, 2005.

[150] M. R. Mancuso, R. Davis, S. M. Norberg, et al., "Rapid vascular regrowth in tumors after reversal of VEGF inhibition," Journal of Clinical Investigation, vol. 116, no. 10, pp. 26102621, 2006.

[151] S. Song, A. J. Ewald, W. Stallcup, Z. Werb, and G. Bergers, "PDGFR $\beta+$ perivascular progenitor cells in tumours regulate pericyte differentiation and vascular survival," Nature Cell Biology, vol. 7, no. 9, pp. 870-879, 2005.

[152] J. L. Yu, J. W. Rak, P. Carmeliet, A. Nagy, R. S. Kerbel, and B. L. Coomber, "Heterogeneous vascular dependence of tumor cell populations," American Journal of Pathology, vol. 158, no. 4, pp. 1325-1334, 2001.

[153] R. S. Bhatt, P. Seth, and V. P. Sukhatme, "Biomarkers for monitoring antiangiogenic therapy," Clinical Cancer Research, vol. 13, no. 2, part 2, pp. 777s-780s, 2007. 


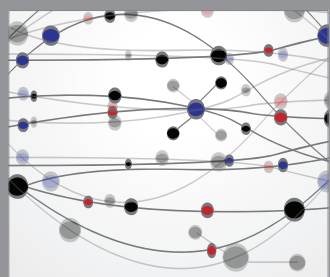

The Scientific World Journal
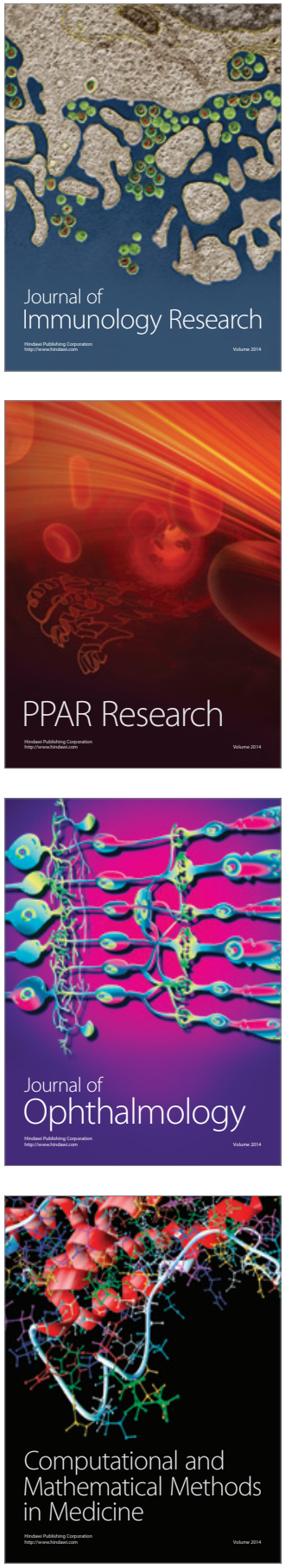

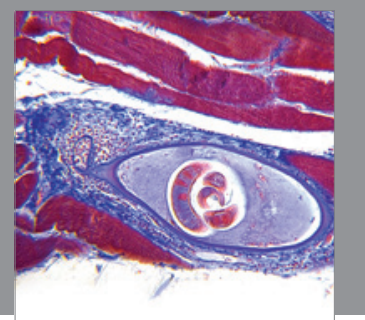

Gastroenterology

Research and Practice
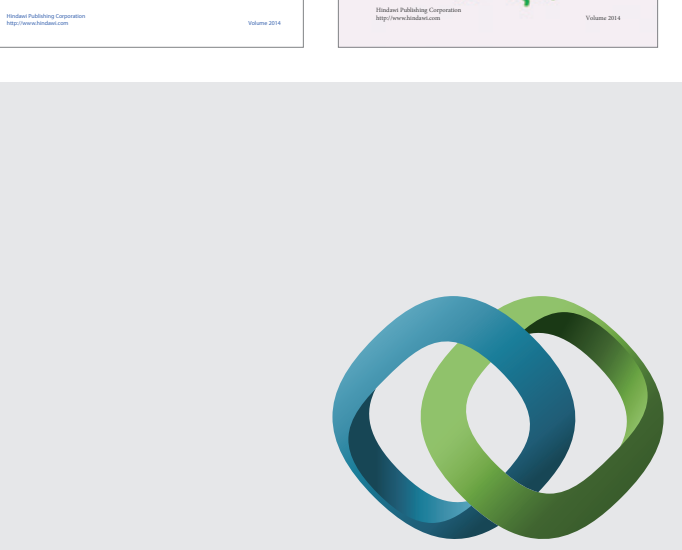

\section{Hindawi}

Submit your manuscripts at

http://www.hindawi.com
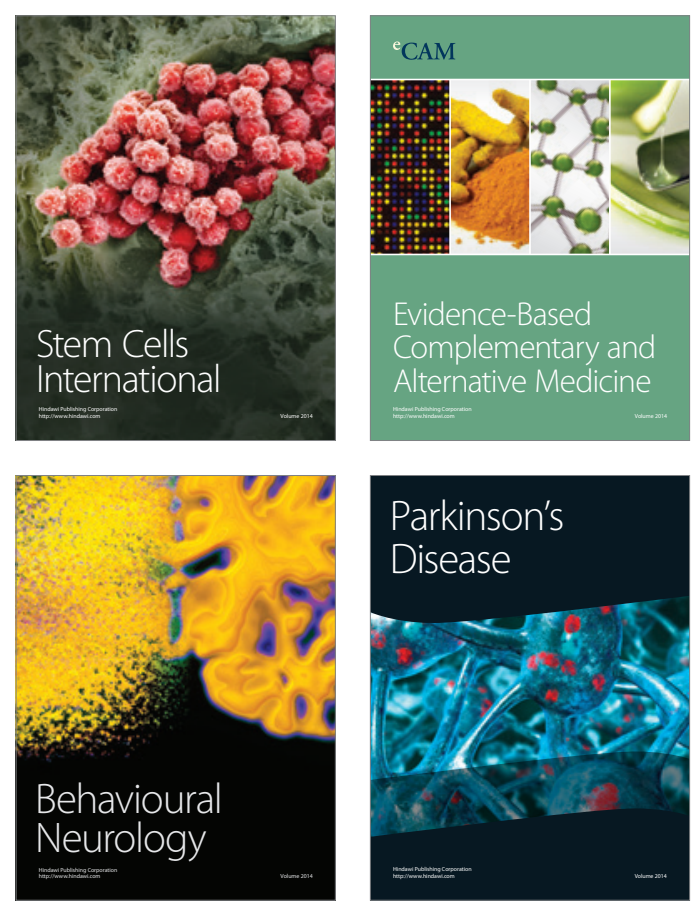

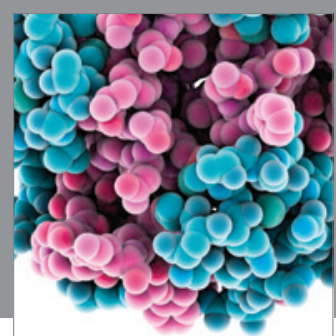

Journal of
Diabetes Research

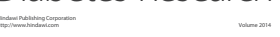

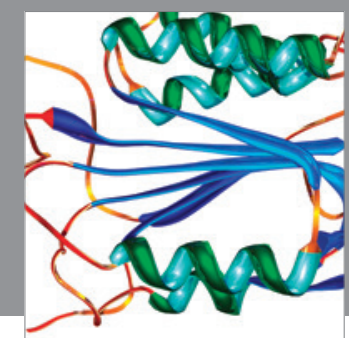

Disease Markers
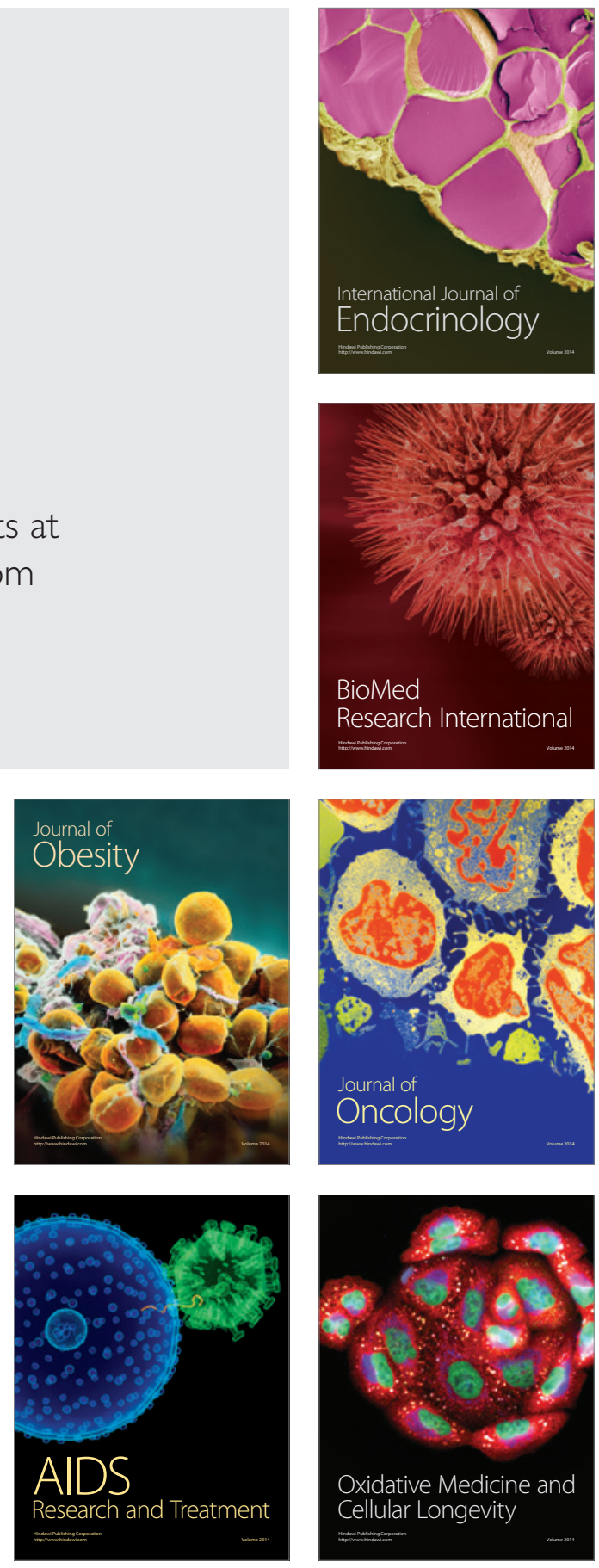